\title{
Op de raaklijn tussen het historische en literaire. Het Vlaamse koloniale proza tot 1960 toegelicht door Luc Renders
}

\begin{abstract}
Publications on Dutch literature about the Belgian Congo that have appeared to date are fragmentary and scattered across scholarly as well as cultural journals, collected volumes, and conference proceedings. There are practically no comprehensive studies on the history of Flemish colonial literature. Koloniseren om te beschaven. Het Nederlandstalige Congoproza van 1596 tot 1960, a recently released book by Luc Renders, aspires to redress this gap in research. Renders' book can be considered the first as wide-ranging and detailed literary-historical exploration of pre-1960 colonial literature, which is presented against an extensive historical background. Crucially, Renders not only compiles the existing research on colonial writings in Dutch, but also contributes to it in an important way.
\end{abstract}

Keywords: Belgian Congo, Flemish colonial literature, colonial writings in Dutch, history of literature, colonisation, Luc Renders.

Een groot deel van de publicaties over de voormalige Belgische kolonie is historiografisch van aard. ${ }^{1}$ Over de Nederlandstalige Congoliteratuur is er betrekkelijk weinig gepubliceerd, wat misschien in verband blijft met haar literaire kwaliteit: deze literatuur wordt namelijk om verschillende redenen negatief beoordeeld. ${ }^{2}$

1 Tot klassieke studies over Congo behoren o.a: Jean Stenghers, Congo, mythes et réalités. 100 ans d'histoire, Paris 1989; Isidore Ndaywel è Nziem, Histoire Générale du Congo, Paris 1998; Georges Nzongola-Ntalaja, The Congo from Leopold to Kabila, London 2002; Adam Hochschild, King Leopold's Ghost. A Story of Greed, Terror and Heroism in Colonial Africa, London 2006; David van Reybrouck, Congo. Een geschiedenis, Amsterdam 2010.

${ }^{2}$ Als motto voor zijn boek kiest Renders wat tegendraads het citaat uit De Menseneter van Koen Peters: "De Congoroman: dat onbenullige genre, met avonturen van paters, jagers en ambtenaren, soms kinderlijk geïllustreerd, vol koloniale daadkracht en de hooggestemde roeping. Ik vond 
Het mag ook verbazing wekken dat men zo lang moest wachten op een "echte" geschiedenis van het genre ${ }^{3}$ die bovendien geschreven zou zijn door een Vlaming. Dit is intussen veranderd met het boek Koloniseren om te beschaven. Het Nederlandstalige Congoproza van 1596 tot 1960 (2019), dat een bekroning vormt van het literair-historische werk van Luc Renders ( $\left.{ }^{\circ} 1948\right)$. Deze emeritus-hoogleraar van de Universiteit Hasselt concentreert zich in zijn wetenschappelijk onderzoek vooral op de Zuid-Afrikaanse literatuur en het Congoproza in het Nederlands. ${ }^{4}$

De thematiek van Renders' boek is treffend bepaald in de titel: het gaat over het Vlaamse koloniale proza tot het jaar 1960 en de ontwikkeling daarvan, nauw samenhangende met het grootscheeps opgezette Belgisch kolonisatieproject dat gerealiseerd wordt onder de dekmantel de beschaving naar Midden-Afrika te brengen.

Het doel van Renders' boek is tweedelig geformuleerd. Enerzijds streeft hij ernaar om een "zo volledig mogelijk overzicht [te] verschaffen over het Nederlandstalige proza over Congo tijdens de koloniale periode, met bijzondere aandacht voor de reis- en verblijfsverslagen, de romans, de novellen en de jeugdliteratuur" (15-16). ${ }^{5}$ Anderzijds wil hij "de Congowerken op hun kolonialistische inslag onderzoeken" (16). Hij analyseert hoe de schrijvers zich positioneren tegenover de kolonisatie en in hoeverre het koloniale gedachtegoed zijn weerspiegeling vindt in hun werk. Renders construeert daarbij zijn betoog traditioneel, zonder gebruik te maken van bijv. postkoloniale theorie, wat voor velen in het geval van het Congoproza een vanzelfsprekende methodologische aanpak zou zijn.

Koloniseren om te beschaven heeft een overzichtelijke structuur (gebaseerd op chronologisch criterium) en bestaat uit drie delen die verder onderverdeeld worden in totaal zestien hoofdstukken van zeer gevarieerde omvang. Het boek begint met

die Congoromans vooral stereotiep en gênant fout: de vet aangezette dromen van jacht en zwarte vrouwen, in een werelddeel waar mensen en dieren nog gelukkig en wild zijn, en ja vandaar de noodzaak van zweep, jachtkarabijn en beschaving" (102). Met zijn boek bewijst Renders echter dat het Congoproza niet te herleiden is tot dergelijke stereotiepe beelden. Hijzelf oordeelt nuchter over dit proza. In gesprek met Horsten (2019) stelt hij dat "De grote Nederlandstalige Congoroman, die de hele geschiedenis in perspectief plaatst, moet nog geschreven worden".

3 Als geschiedenissen van de Vlaamse Congoliteratuur fungeren bijv. Het koloniale in de literatuur (1938) van Sylva de Jonghe en Geschiedenis van de Vlaams-Afrikaanse letterkunde (1961) van Verthé en Henry. De contemporaine Nederlandse literatuurgeschiedenissen, zoals die van Bel (2016) en Brems (2006), geven slechts een bescheiden inzicht in de Congoliteratuur.

${ }^{4}$ Renders publicaties gelden als wezenlijke referentiewerken voor het onderzoek naar de Congoliteratuur, bijv. "Kolonialistische en anti-kolonialistische tendensen in de Vlaamse Kongo-letterkunde: Het Vlaams-Afrikaanse proza en het kolonialisme" (1994), "De wrede tropen: kritisch Nederlandstalig Kongo-proza" (1996), "Nikkerke en ikkerke. Nederlandstalig proza over Kongo" (2002) of "De kloof tussen ideaal en realiteit" (2006). In 2020 heeft hij samen met Jeroen Dewulf de allereerste bloemlezing van Vlaams Congoproza in Engelse vertaling laten verschijnen: The Congo in Flemish Literature: An Anthology of Flemish Prose on the Congo, 1870s-1990s.

5 Alle citaten in de hoofdtekst zijn ontleend aan het boek Koloniseren om te beschaven. 
een inleiding en besluit met een soort beknopt overzicht van voorgaande bevindingen ("Terugblik: met haast volkomen eensgezindheid", 445-454), eindnoten, bibliografie en auteursregister, maar mist wel een aparte lijst met de titels van alle vermelde Congowerken en een lijst van opgenomen grafieken (o.a. enkele zwart-witte kaarten). Daarnaast ontbreekt er een zaakregister met behulp waarvan men makkelijker informatie zou kunnen opzoeken in deze omvangrijke tekst.

Afzonderlijke delen of hoofdstukken worden ingeleid met een vrij gedetailleerde karakterisering van drie historische periodes (respectievelijk Congo voor 1885, Congo in de jaren 1885-1908 en 1908-1960). Het boek is rijk aan citaten, vooral uit besproken werken, maar ook uit andere bronnen: de auteur heeft zo de vrijheid genomen om bijv. de volledige versie van Lumumba's beroemde speech uit 1960 op te nemen (265-268).

De inhoud van de meeste prozawerken wordt kort samengevat, en bij koloniale sleutelwerken krijgt de lezer een wat uitgebreidere presentatie van plot, hoofdpersonages en centrale motieven. De omvang van biografische informatie die verstrekt wordt over afzonderlijke schrijvers is vooral mede bepaald door hun betekenis voor de Vlaamse koloniale literatuur. Hier moet een verdienste van Renders' boek benadrukt worden: het introduceert vele "nieuwe" auteurs (o.a. Simon Smits, Antoon Greshoff, J. Esra, Bert Fierens, Robrecht De Sadeleer) en hun werk in de Vlaamse literatuurgeschiedenis.

Volgens Renders kunnen alle Congowerken in een van de drie categorieën ondergebracht worden: kolonialistisch of pro-koloniaal, kolonialistisch-kritisch en anti-kolonialistisch. Zijn onderzoek laat goed zien dat de meerderheid van de literaire productie uit de koloniale periode de officiële koloniale propaganda en het koloniaal beleid verdedigt: "De koloniale literatuur zingt haast unisono de lofzang voor de kolonisatie die alleen maar weldaden brengt" (454). Ook de Vlaamse koloniale kinder- en jeugdliteratuur is hier geen uitzondering op de regel en wordt als propagandistisch instrument gebruikt, geschikt om nieuwe pro-koloniale generaties op te voeden (433-444). Slechts weinige Congoteksten zouden een uitgesproken kritische, anti-kolonialistische strekking hebben.

In Deel I ("Voor 1885: de lange aanloop tot de kolonisatie van Midden-Afrika", 19-96) houdt Renders zich overwegend met historische vraagstukken bezig, zoals de contacten tussen Europa en Midden-Afrika die voorafgingen aan de kolonisatie of de koloniale ambities van Leopold II en de realisatie ervan. Zijn verhaal over het Congoproza laat hij weliswaar al in 1596 beginnen, toen Martijn Everart het "eerste overzichtswerk over Kongo" van de Italiaan Pigafetta heeft vertaald en als De Beschryvinghe vant Groot ende Vermaert Coninckrijck van Congo uitgegeven (26), maar over het algemeen zijn de Vlaamse teksten over Congo (meestal reisverslagen) in de periode voor 1885 nog schaars. Renders wijst op Batavia (1858) van Hendrik Conscience als de eerste Vlaamse koloniale roman en op twee sketches van Cyriel Buysse uit Verslagen over den Gemeenteraad van Nevele als 
"de eerste Vlaamse literaire teksten over Congo" (92). In deze fictieve verslagen van vergaderingen van 9 april 1885 en van juni 1886, met Congo op hun agenda, wordt de Belgische beschavingsopdracht in Congo onverwacht kritisch als een absurde onderneming voorgesteld.

Deel II ("Van 1885 tot 1908: van utopie naar dystopie", 97-218) beslaat de tijd van de beruchte Congo Vrijstaat. In de koloniale werken uit die periode valt van gruwelijkheden (uitbuiting en mishandeling van de Congolezen) nauwelijks iets te bespeuren. De koloniale literatuur staat meer in het teken van "zelfopoffering" van dappere Belgische pioniers die hun leven geven "voor de redding van de Afrikanen" (Renders 447). Vooral katholieke missionarissen en protestantse zendelingen hebben toen over Congo geschreven, maar ook ambtenaren en bezoekers. Het beeld van de koloniale realiteit dat uit hun teksten naar voren komt, is over het algemeen vertekend en misleidend, vooral over het Belgisch beschavingswerk. Over wantoestanden hebben ze niet expliciet bericht. De schrijvers die wel een zekere kritiek uiten op de situatie in Congo blijven in de minderheid (o.a. Cyriel Buysse met zijn klassieker De zwarte kost of de Nederlander Henri van Boven). Als "het eerste Vlaamse fictiewerk over Congo geschreven door een auteur tijdens zijn verblijf aldaar" (145) geldt de pro-koloniale novelle Ook een ideaal (1896) van Pieter Danco, een liefdesgeschiedenis in "hyperromantische stijl" waar Congo slechts als "exotische locatie" dient (145).

Het meest omvangrijke Deel III $^{6}$ ("Van 1908 tot 1960: Belgisch Congo onder paternalistisch bestuur", 219-444) bestrijkt de periode waarin de literaire productie over de kolonie zich intensief ontwikkelt en onderscheidt door grote diversiteit qua vorm en problematiek. Merkbaar wordt de toenemende belangstelling voor de Congolese talen en culturen, wat gepaard gaat met het ontkrachten van schadelijke stereotypen en langzamerhand resulteert in groeiende waardering voor de Congolezen zelf. In die lange periode wordt zowel koloniale non-fictie als ook fictie geschreven. Boeken met pro-koloniale strekking worden nog steeds in groten getale gepubliceerd (Adolf Verreet, Fernand Goddemaer e.a.). De kolonialistisch-kritische stroming wordt vertegenwoordigd o.a. door Frans Beckers (ook bekend als Frans Demers en J.M. Elsing; 369-386), Sylva de Jonghe (386-402) en door Gerard Walschap en zijn Oproer van Congo (1953), waarin opgeroepen wordt "tot een kolonisatie "met een menselijk gelaat" (407). De enige auteur voor 1955 wiens werk als anti-kolonialistisch omschreven kan worden, zou René Poortmans (412-413) zijn. Later wordt het proza van Piet van Aken zo bestempeld: zijn novelle De nikkers (1959) is een van die werken die "de legitimiteit van de kolonisatie volledig ondermijnen" (427).

Met zijn boek biedt Renders een omvangrijke historische kaderschets van het proza over Belgisch Congo. Zijn werk plaatst zich duidelijk op de raaklijn tussen historiografie en literatuurwetenschap, wat de beoordeling ervan enigszins ver-

${ }^{6}$ In de inhoudsopgave abusievelijk aangeduid als Deel II. 
moeilijkt. De professionele historicus zou al lezende misschien kunnen verzuchten dat de voorstelling van bepaalde feiten of historische processen niet genoeg genuanceerd is, onjuistheden bevat of te veel berust op verouderde bronnen. ${ }^{7}$ In de ogen van een literatuurhistoricus lijkt Renders echter hier en daar te veel in te gaan op de historische details van de kolonisatie en tegelijk te weinig op de mogelijke correlaties tussen die vermelde gebeurtenissen en specifiek literaire verschijnselen. De meer literair georiënteerde lezer zou zich kunnen afvragen in hoeverre zo'n uitgebreide historische component functioneel is. Niettemin is Koloniseren om te beschaven een onmisbaar naslagwerk voor iedereen die zich bezighoudt met onderzoek naar de Nederlandstalige Congoletterkunde of gewoon geïnteresseerd is in het koloniale verleden van België. Het is namelijk de eerste zo degelijke poging om deze literatuur te presenteren aan de huidige lezers, die allerlei literaire en historische contexten missen. Renders' boek laat de Congoliteratuur zien in haar vele complexe en dubbelzinnige verwikkelingen, beschrijft in teksten bewaarde ideeën en houdingen ten opzichte van de kolonisatie en toont daarmee de geleidelijke transformatie van de koloniale mentaliteit. Het is een boek waaraan allang een behoefte bestond: veel waardevolle gegevens over koloniale Vlaamse schrijvers en hun werk - tot nu toe verspreid over diverse publicaties of daar helemaal niet opgenomen - worden uiteindelijk bijeengebracht. Het enige wat nu nog rest, is wachten op een vervolg, met het verhaal over het Congoproza na 1960.

Luc Renders, Koloniseren om te beschaven: het Nederlandstalige Congoproza van 1596 tot 1960, Gramadoelas, 2019, ISBN 9789463886666, 496 pp.

\section{Bibliografie}

Bel, Jacqueline. Bloed en rozen. Geschiedenis van de Nederlandse literatuur 1900-1945. Bert Bakker, 2016.

Brems, Hugo. Altijd weer vogels die nesten beginnen. Bert Bakker, 2006.

Horsten, Toon. "In dienst van kerk, staat en industrie. Interview Luc Renders over de Nederlandstalige Congoliteratuur". De Standaard, 18.10.2019, https://www.standaard.be/cnt/dmf2019 1017_04669064. Geraadpleegd 20 juni 2021.

Peeters, Koen. De menseneter. De Bezige Bij, 2017.

Renders, Luc. "De kloof tussen ideaal en realiteit". Wandelaar onder de palmen. Opstellen over koloniale en postkoloniale literatuur, geredigeerd door Michiel van Kempen et al. KITLV, 2004, pp. 389-399.

---. "De wrede tropen: kritisch Nederlandstalig Kongo-proza". Tydskrif vir Nederlands en Afrikaans, no. 2, 1996, pp. 176-195.

7 Op zijn historiografische kwaliteiten wordt Renders' werk bijv. door Zana Etambala (2020) beoordeeld. 
---. "Kolonialistische en anti-kolonialistische tendensen in de Vlaamse Kongo-letterkunde: Het Vlaams-Afrikaanse proza en het kolonialisme". Literatuur, vol. 11, no. 1, 1994, pp. 158-165.

---. "Nikkerke en ikkerke: Nederlandstalig proza over Kongo". Europa buitengaats. Koloniale en postkoloniale literaturen in Europese talen, geredigeerd door Theo d'Haen. Bert Bakker, 2002, pp. 302-328.

Zana Etambala, Mathieu. "Zo schreven wij over Congo. Koloniseren om te beschaven van Luc Renders". 18.08.2020, https://www.de-lage-landen.com/article/zo-schreven-wij-over-congo. Geraadpleegd 7 juli 2021. 